eighteenth than to the nineteenth and twentieth century varieties. Morality originates in sentiments of approbation, and at the centre of this field of affectionate approval is human wellbeing. Politics is a matter of compromise made possible by widespread but imperfect agreements in judgement. Medical practice, social policy and education are about promoting and protecting the interests of human kind. Regular readers of the JME will engage most directly with the first 100 pages in which Warnock's liberal, humanist, intuitionistic welfarism is directed towards questions of life, death, experimentation and paternalism; but there is much to enjoy, and to be informed by, in later chapters.

JOHN HALDANE Department of Moral Philosophy, University of St Andrews

\section{Christian ethics in health care}

John Wilkinson, Edinburgh, Handsel Press, 1988, £27.50

The appearance in 1994 in the JME of a review of a book published in 1988 is not due to dilitariness on the part of the reviewer but to an editorial decision that it ought to be noticed; rightly so, because it is a substantial achievement, not to be overlooked because it is specifically written for Christian doctors, nurses and other health care professionals. Its author is a graduate of Edinburgh University in both divinity and medicine. He spent 30 years in medical missionary work in Kenya and then, before retirement, was a community medicine specialist for the Lothian Health Authority. The sub-title tells us that this is a source book, and indeed it is more likely to be used for reference than continuous reading. There are three parts. The first two are relatively brief, "Christian ethics in outline' and 'Health care ethics in history'. The rest of the book, from page 163, deals with a range of issues in health care: those concerned with the beginning and end of life; with experiments on human subjects and the question of consent; with the allocation of health care resources; with relations between health care professionals and with the public, and with AIDS.

Wilkinson remarks that writing a book on these issues is like trying to hit a moving target; but he was up-todate in 1988, as the extensive references to American and UK medical literature show, and I do not think things have changed very much since then, so that the book will be useful for several more years. The pros and cons of most issues are given, and not just Wilkinson's own stance. There is a robust realism in his approach to the allocation of resources and to questions of relationships within the health care professions.

In Christian theology and ethics the author is not quite so expert as he is in medicine but, more important, his stance is clearly 'evangelical'. This shows particularly in the bibliography and in the attitude to the Bible. However, there are a number of references to Roman Catholic sources and teaching, and these are clear and up-to-date (including the revised Code of Canon Law of 1983). As to the Bible, Wilkinson is inclined to move too simply from the text to current problems, as from the feeding of the 5,000 to resource allocation, or in the attitude to homosexuality. $\mathrm{He}$ is no fundamentalist but he is prone to be literal in his use of texts, as in the case of the Fall. Also he makes the common evangelical assumption that if one's character is right and good so will be one's conduct (page 164). But the concern of the book for accurate information and diagnosis shows that in practice he sees that more than good motives are needed.

RONALD PRESTON Emeritus Professor of Social and Pastoral Theology in the

University of Manchester

\section{Creation and abortion: a study in moral and legal philosophy}

F M Kamm, 227 pages, New York, 1992, Oxford University Press, $£ 25.00$ hc, $£ 8.95$ pc

The pro-life argument that abortion is immoral says that a human fetus has the same moral standing as a human adult and that abortion, by killing the fetus, violates its right to life. A prochoice response can either deny that the fetus has moral standing or argue that even if it does have standing, abortion does not violate its rights.
Common though it is, the first response is hard to make decisive. There are strong arguments against the view that moral standing is acquired at conception, but there seem also to be persuasive arguments against other proposed cutoff points, such as the start of brain activity, viability, and birth. Hence the attractiveness for a pro-choice position of the second response: show that even if the fetus does have rights, abortion is not wrong.

This line was first taken in Judith Thomson's 'A defense of abortion' (1). Thomson compared having an unwanted pregnancy to being kidnapped by a Society of Music Lovers and forcibly attached to a famous but ailing violinist. The violinist needs to use one's kidneys for nine months; otherwise he will die. $\mathrm{He}$ is innocent and has a right to life. Yet surely, Thomson argued, one is morally permitted to unplug oneself from him. Similarly, a woman is often permitted to abort a fetus.

Striking though it is, Thomson's analogy has several flaws. The violinist may be innocent, but he is the beneficiary of other people's guilty action. In unplugging him, one merely foresees but does not intend his death. Arguably, one also merely allows him to die, rather than killing him.

F M Kamm is aware of these and other difficulties with Thomson's analogy. But she believes that a position like Thomson's can be shown to be reasonable, if not incontrovertibly true. Doing so is the task of her brilliant but difficult book Creation and Abortion.

Kamm begins by discussing nonabortion cases of bodily attachment, such as that of the famous violinist. She argues that one is permitted intentionally to kill the violinist - not just unplug him - if that is necessary to avoid something as serious as the invasion of one's bodily integrity. A main reason is that killing the violinist deprives him only of a life that depends on one's support; that is, killing does not harm him relative to his position before attachment.

Kamm then extends this argument to abortion cases, distinguishing pregnancies due to rape, voluntary pregnancies, and pregnancies that were foreseen but not intended. But here she finds a difficulty: the extended argument implies that a woman who has an abortion after getting pregnant as a summer project - just to see what it is like - does nothing wrong. The woman's fetus is 
no worse off than before it was conceived, yet surely her behaviour is morally objectionable.

To handle this case, Kamm proposes that it is, other things equal, wrong to create a person whose life will not contain some minimum number of years at a minimal level of welfare, one somewhat higher than makes a life better than nothing. (This is part of what she calls 'creating responsibly'.) But how much does one owe to a fetus to ensure that it either is not created or enjoys these minima? In particular, does one owe it as much as sexual abstinence or carriage through pregnancy? Kamm argues that given certain reasonable moral claims, for example, about the value of sexual activity, and certain facts, for example, that there are no completely safe and effective contraceptives, one does not owe a fetus this much. Just as one may kill the violinist to avoid a bodily invasion, so one may fail to provide a fetus with the minima if doing so is sufficiently costly. It is reasonable to hold, she concludes, that even if a fetus has rights, in many cases aborting it is not wrong.

This brief summary cannot do justice to the richness of Kamm's discussion. She raises many new issues about abortion and consistently makes insightful points about them. But her book is not easy to read. This is partly because of the complexity of its contents; Kamm rightly believes that many factors are relevant to a Thomson-style argument about abortion. But she does not give as much guidance as she should through this complexity. Her book contains few signposts explaining how a particular discussion fits into its larger argument; the reader is left to work out what is central and what is a digression. There is not even a conclusion summarizing Kamm's main results. If it is true that God dwells in the details, this is an excessively God-inhabited book.

These weaknesses of exposition are unfortunate, for if one works through them, Creation and Abortion is a sophisticated and exciting discussion of a neglected aspect of the abortion debate.

\section{References}

(1) Thomson J. A defense of abortion. Philosophy and public affairs 1971; 1: 47-66.

\section{Whose life is it anyhow?}

Simon L Cohen, 206 pages, London, 1993, Robson Books, £16.95

Cohen's snappily paced book is selfavowedly an attempt 'to elicit public support to ensure continuing adequate intensive care life saving facilities' (page ix). Its twenty-three chapters, averaging about nine pages each, touch upon many largely familiar areas of ethical concern in the ITU without appearing to grapple with any of them.

The approach is case-based to the extent that about 20 per cent of the text is taken up with narratives of cases that Cohen has seen in his work. Unfortunately, these histories are more of an alternative to, than illustrations of, philosophical discussion. Cohen falls victim to the common fallacy that a plethora of examples shows something new, rather than giving one example and wrestling with its difficulties. Nevertheless, many of his cases are fascinating, especially to a non-medic to whom they are new, but this unbridled proliferation means the book tends to read like an intensivist's diary rather than a work of medical ethics.

One theme that runs through the book is the tension - in the scenario of limited resources - in 'spending a very large proportion of one's public health resources on a very small number of patients' (page 8). Cohen's conviction that this is the right thing to do allows no discussion of any alternative position: any idea of stratifying the acutely ill 'conjures images of an ICU doctor conniving with his infamous colleague Mengele' (page 30). His own position is quite clear, that the only acceptable criterion for prioritising patients is medical need.

Given this (unargued for) position, it is strange that Cohen concludes that 'it is important that the public is able to discuss and indeed express views about these ethical dilemmas so that it is the general public and not the doctor who controls life' (page 199). One thing we can be sure of is that those best qualified to assess medical criteria are doctors, not the general public, and that whatever criteria the latter use are unlikely to be purely medical.

Moreover, if all there is to resource allocation decisions is an estimate of medical need, then the question ceases to be a moral one at all. The question, then, is whether Cohen's notion of medical decision-making is value-free or not. If it is, then it is harch. to see that the dilemma is a moral one: If, on the other hand, it is not, ther why should it have any kind of priority over value-laden decisions?

The book as a whole is an interest ing example of a familiar medical posi $-\frac{\pi}{T}$ tion that holds that most problems can be solved by a combination of̂ improving the quality of the diagnosis and making more money available? Philosophically, it is neither particu $\overrightarrow{-}$ larly clear nor original, nor is it welf referenced enough to facilitate furthe study. Its quick-fire approach to 2 variety of ethical dilemmas, combinedu with a wealth of the kind of dramatic cases that have made the BBC'sCasualty such a success should appea $\mathrm{L}$ to its target audience, the generab' public. The danger is that its acces 0 sible if somewhat superficial treatment of these questions might lull the general reader into thinking that there was nothing more to them. It would be a valuable addition to any publice library, if a little out of its depth in academic one

Centre for Philosophy and Health CAिe University College of Swarisea

\section{The medical school's mission and the population's health}

Edited by Kerr L White and Julia E Connelly, 281 pages, New York, 1992, Springer-Verlag, Dm 118.00

This book records the proceedings of $\mathbb{D}$ four-cornered (US, UK, Canada Australia) meeting which waș organised with the central purpose of defining the mission of the medicab school and, particularly, of establishing its position vis-à-vis the community The book consists of nine main papersw with additional prepared discussion The general premise is that medicad faculties have lost interest in the healtif of populations and that curren? teaching methods are concentrated on specialties and even narrower sub $\overline{0}$ specialties. The recurring theme is tha this does not produce ideal generaf practitioners - leading to a feeling os deja vu, for this is something we have known for more than half a century.

Medical schools are said to have a social contract with the populations 